\title{
SPOT THE DIFFERENCE
}

Delilah the DCP is enjoying

the summer sunshine, relaxing

in the garden with the latest

copy of Vital. But can you

spot the ten differences

between these two pictures?
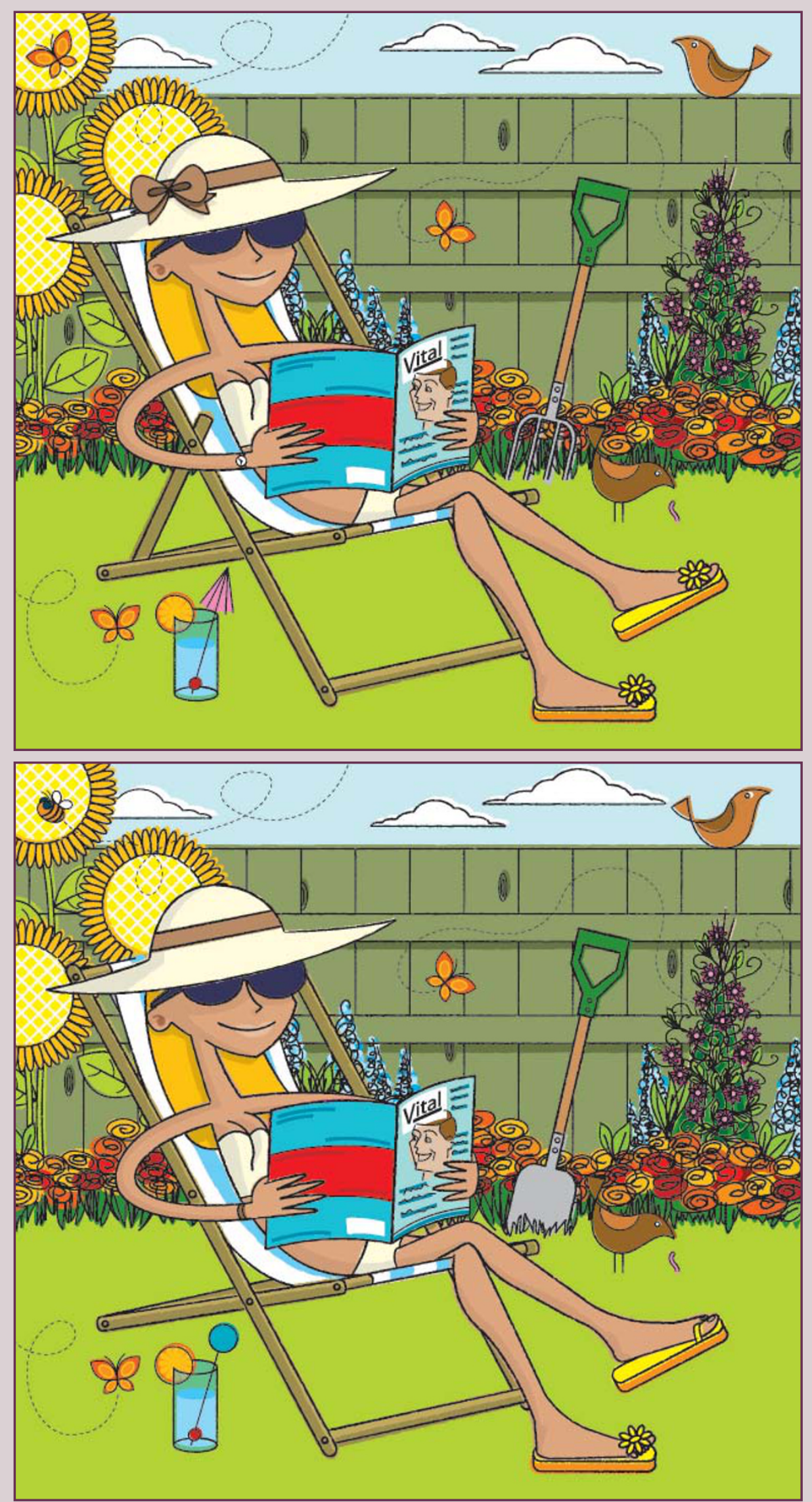

Solution: see page 60. 